\title{
Gas chromatography/mass spectrometry demonstration of steryl glycosides in eucalypt wood, Kraft pulp and process liquids
}

\author{
Ana Gutiérrez and José C. del Río* \\ Instituto de Recursos Naturales y Agrobiología de Sevilla, CSIC, P.O. Box 1052, 41080-Seville, Spain \\ Received 24 October 2001; Accepted 28 October 2001
}

SPONSOR REFEREE: Prof. Bjarne Holmbom, Åbo Akademi, Åbo, Finland

\begin{abstract}
The occurrence of steryl glycosides (SG) and acyl steryl glycosides (ASG) in eucalypt (Eucalyptus globulus) wood has been investigated. These compounds were analyzed as their trimethylsilyl ethers by gas chromatography/mass spectrometry (GC/MS) using a $15 \mathrm{~m}$ length high-temperature capillary column with a thin film, and identified on basis of their mass spectra and relative retention times comparing with those of authentic standards. Significant amounts of SG were identified in eucalypt wood whilst only traces of ASG could be detected. Eucalypt SG and ASG occur in the pyranoside form, which is readily distinguishable from the furanoside configuration by the mass spectra of their trimethylsilyl derivatives. The sterol part of the SG and ASG consisted of sitosterol, being sitosteryl $3 \beta$-D-glucopyranoside and sitosteryl (6'-O-palmitoyl)-3 $\beta$-D-glucopyranoside, the major SG and ASG found in E. globulus wood. The presence of SG and ASG was also investigated after kraft cooking by analyzing unbleached pulp and process water samples. The GC/MS results also revealed the presence of sitosteryl $3 \beta$-D-glucopyranoside in these samples. By contrast, no ASG could be detected. Therefore, we have shown that SG survive the kraft cooking and can be found at least partly intact after pulping, being a possible cause for pitch deposits together with free and esterified sterols. Copyright $($ C) 2001 John Wiley \& Sons, Ltd.
\end{abstract}

Similar to other eukaryotic organisms, plants produce a variety of sterols and sterol derivatives. The most common transformation of free sterols (FS) in tissues of vascular plants is the conjugation at its 3-hydroxy group with longchain fatty acids to form steryl esters (SE), or with carbohydrates to form steryl glycosides (SG). Some of the SG molecules present in plant cells are additionally esterified at the 6-hydroxy group of the carbohydrate moiety with longchain fatty acids, to give acyl steryl glycosides (ASG). SG have been reported in various higher plants, ${ }^{1-3}$ along with the ASG and FS and SE.

Previous research on Eucalyptus globulus wood has shown that FS and SE form a considerable percentage of the total lipophilic extractives. ${ }^{4}$ The composition and fate of sterol lipids from eucalypt wood have been investigated in detail for their relevance in some technical and economic problems during the production of kraft pulp due to the formation of the so-called pitch deposits. ${ }^{5-9}$ During wood pulping and refining of pulp, lipophilic extractives (resin) are released forming colloidal pitch, which can deposit on the surfaces of

*Correspondence to: J. C. del Río, IRNAS-CSIC, P.O. Box 1052, 41080 Seville, Spain.

E-mail: delrio@irnase.csic.es

Contract/grant sponsor: The European Commission; Contract/ grant number: QLK5-99-1357.

Contract/grant sponsor: Spanish Comisión Interministerial de Ciencia y Tecnología; Contract/grant number: IFD97-0742. fibers or equipment, and are thus responsible for production troubles. ${ }^{10}$ In the production of bleached kraft pulp, a large part of the resin originally present in wood is removed during the cooking and bleaching. However, some chemical species survive these processes and are found as pulp extractives, are suspended in process waters, or form deposits. On the other hand, other sterol derivatives such as SG and ASG have not been previously identified in eucalypt wood although they may also have a relevant role in the formation of pitch deposits. SG have already been found in small amounts in other wood species, such as aspen, ${ }^{11}$ white oak, ${ }^{12}$ spruce, $^{13}$ birch $^{14,15}$ and pine. ${ }^{16}$ However, to our knowledge no studies have been conducted so far to investigate the presence of these compounds in eucalypt wood, the most important raw material for paper pulp production in Spain and many other countries.

Analysis of SG and ASG has usually been performed after hydrolysis and subsequent analysis of the steroid and carbohydrate moieties. On the other hand, intact SG and ASG have also been analyzed by ${ }^{1} \mathrm{H}$ and ${ }^{13} \mathrm{C}$ NMR (nuclear magnetic resonance) to determine the configuration of the carbohydrate moiety as well as the identity of the sterol part. However, by preparing the trimethylsilyl (TMSi) ethers of the intact glycolipids, it is also possible to obtain direct evidence for their structures from mass spectrometry. ${ }^{1,3,17}$ In this paper we report, for the first time to our knowledge, the occurrence of steryl glycosides in E. globulus wood as well as in pulp and process waters during manufacturing of 


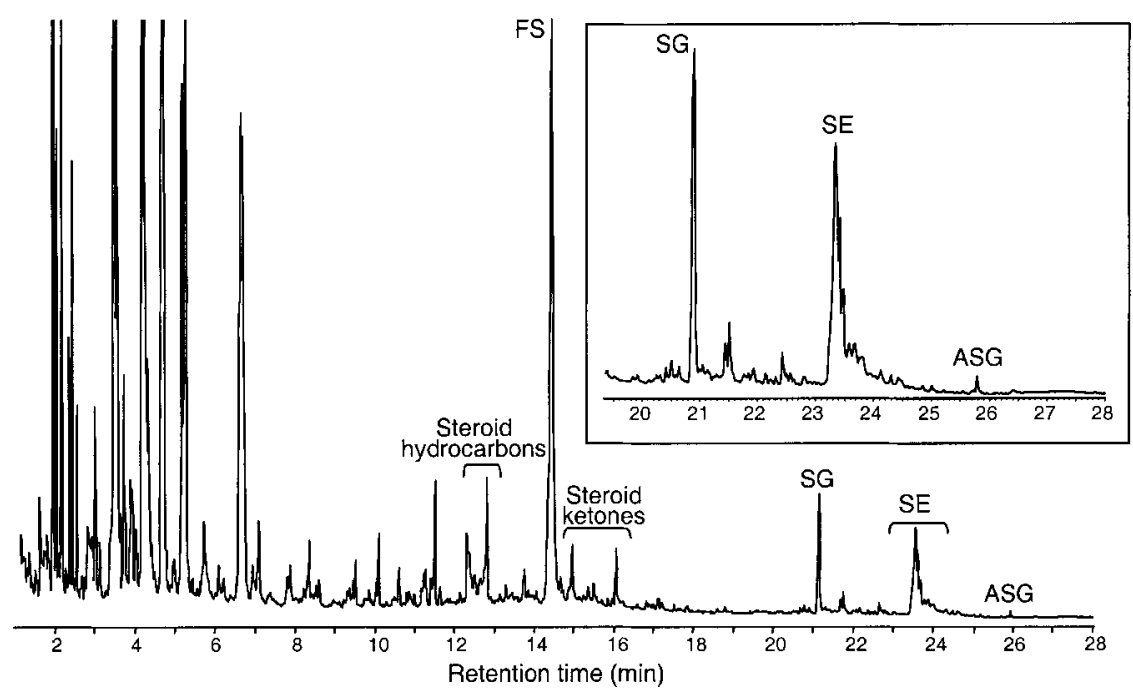

Figure 1. Total-ion chromatogram of the acetone-soluble extract of $E$. globulus wood (after BSTFA derivatization). The inset shows a partial GC/MS trace from a more concentrated sample to show the ASG peaks.

eucalypt kraft pulp. The analysis of SG and ASG was accomplished by gas chromatography/mass spectrometry (GC/MS) as their TMSi ethers.

\section{MATERIAL AND METHODS}

\section{Samples of eucalypt wood, unbleached pulp and process waters}

The samples used in this study were provided by the ENCE pulp mill in Pontevedra (Spain). This mill produces paper pulp from E. globulus wood by kraft pulping and totally chlorine-free (TCF) bleaching. The trees were cut at an age of 12-14 years, subsequently debarked and ground to sawdust. The unbleached pulp sample was collected after the kraft cooking and several washing stages, and a sample of this washing water was also collected. The wood sawdust and the dried pulp were Soxhlet extracted with acetone for $6 \mathrm{~h}$. The process water sample was extracted three times in a separatory funnel with a mixture of hexane/acetone $(2: 1)^{18}$ at $\mathrm{pH}$ 12. After the extractions, the solvents were evaporated to dryness under vacuum. The dried extracts were silylated with bis(trimethylsilyl)trifluoroacetamide (BSTFA) in the presence of pyridine at $80^{\circ} \mathrm{C}$ for $90 \mathrm{~min}$ before GC/MS analyses.

\section{GC/MS}

The analyses were performed using a gas chromatograph coupled to a quadrupole mass spectrometer detector (Model Voyager, ThermoQuest Finningan, San Jose, CA, USA) equipped with a fused-silica capillary column (DB-5HT, J\&W; $15 \mathrm{~m} \times 0.25 \mathrm{~mm}$ i.d., $0.1 \mu \mathrm{m}$ film thickness). The oven was heated from $120^{\circ} \mathrm{C}(1 \mathrm{~min})$ to $380^{\circ} \mathrm{C}(5 \mathrm{~min})$ at $10^{\circ} \mathrm{C} /$ $\mathrm{min}$. The injector (split-splitless) and transfer line temperatures were set at $300^{\circ} \mathrm{C}$ and $350^{\circ} \mathrm{C}$, respectively. Helium was used as carrier gas and the injection was performed in splitless mode. The electron impact (EI) mass spectra $\left(1 \mathrm{scan} \mathrm{s}^{-1}\right)$ were acquired from $\mathrm{m} / \mathrm{z} 50$ to 800 . The compounds were identified by comparing the retention times and mass spectra obtained with those of authentic standards and by mass spectral interpretation. Standards of campesteryl, stigmasteryl and sitosteryl $3 \beta$-D-glucopyranosides and campesteryl, stigmasteryl and sitosteryl (6'-O-palmitoyl)-3 $\beta$-Dglucopyranosides (supplied by Matreya, Inc., Pleasant Gap, PA, USA) were used to corroborate the identifications made by GC/MS. A mixture of the standard compounds with a

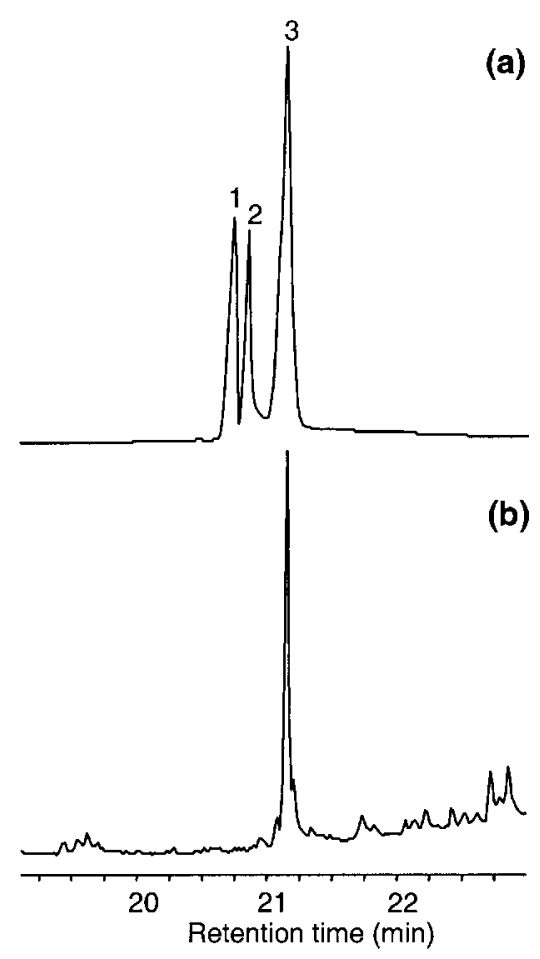

Figure 2. Comparison of partial gas chromatograms of (a) authentic SG standards (1, campesteryl 3 $\beta$-Dglucopyranoside; 2 , stigmasteryl $3 \beta$-D-glucopyranoside; and 3 , sitosteryl $3 \beta$-D-glucopyranoside) and (b) the acetone extract from E. globulus wood showing the peak of SG (after BSTFA derivatization). 
concentration range between 0.1 and $1 \mathrm{mg} / \mathrm{mL}$ was used to obtain a calibration curve for their quantitation. The correlation coefficient was higher than 0.99 in all cases. All peaks were quantified by area.

\section{RESULTS AND DISCUSSION}

The analysis of SG and ASG, as their TMSi ethers, was accomplished by GC/MS using medium-length high-temperature capillary columns with thin films. ${ }^{19}$ This method enables the elution and separation of high molecular mass lipids. The total-ion chromatogram of the lipid extract of $E$. globulus wood after BSTFA derivatization is shown in Fig. 1. Free and esterified sterols are among the major lipophilic compounds in eucalypt wood. In both cases the main sterol identified was sitosterol, followed by stigmastanol, and minor amounts of fucosterol, citrostadienol, cycloartenol, 24methylenecycloartanol and campesterol. ${ }^{4}$ Peaks corresponding to SG and ASG were identified in the high molecular mass region of the chromatogram only after BSTFA derivatization of the E. globulus wood extract (Fig. 1, inset). The identification of SG and ASG was accomplished by comparison with the mass spectra and relative retention times of authentic standards.

Figure 2 shows a comparison of the total-ion chromatograms of a mixture of SG standards (campesteryl, stigmasteryl and sitosteryl $3 \beta$-D-glucopyranosides) as TMSi derivatives, and the E. globulus wood extract. The retention time of the SG present in eucalypt wood is coincident with that of peak 3 (sitosteryl $3 \beta$-D-glucopyranoside) of the standard mixture. Moreover, the mass spectrum of the SG peak present in E. globulus wood is also identical to that of the
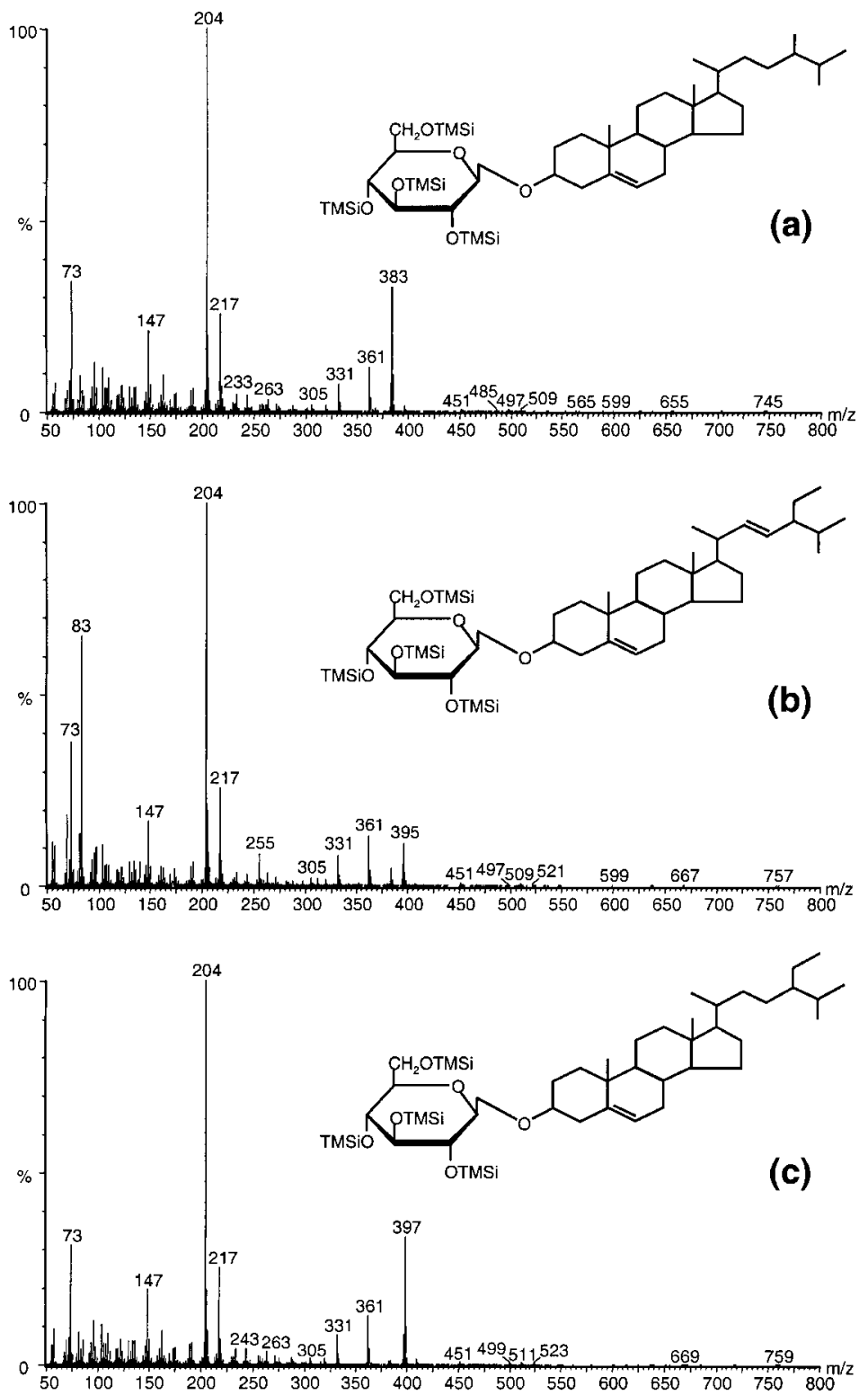

Figure 3. El mass spectra and structures of the TMSi ethers of (a) campesteryl 3 $\beta$-D-glucopyranoside, (b) stigmasteryl 3 $\beta$-Dglucopyranoside and (c) sitosteryl 3 $\beta$-D-glucopyranoside 


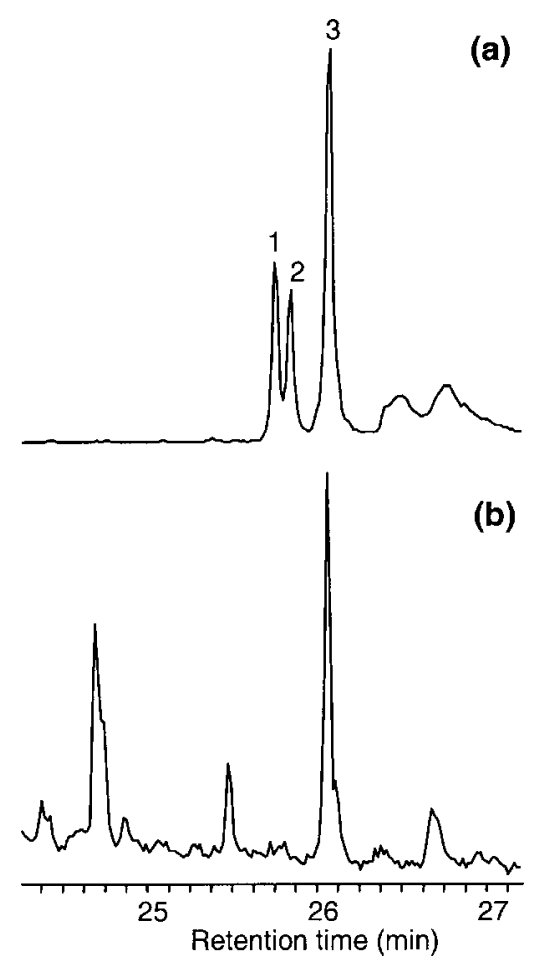

Figure 4. Comparison of partial gas chromatograms of (a) authentic ASG standards (1, campesteryl (6'-O-palmitoyl)$3 \beta$-D-glucopyranoside; 2 , stigmasteryl (6'-O-palmitoyl)-3 $\beta$-Dglucopyranoside; and 3 , sitosteryl (6'-O-palmitoyl)-3 $\beta$-Dglucopyranoside) and (b) the acetone extract from $E$. globulus wood showing the peak of ASG (after BSTFA derivatization).

sitosteryl $3 \beta$-D-glucopyranoside standard. These spectra show the characteristic fragments for the TMSi ethers of hexoses and sterols, typical of steryl glycosides. ${ }^{1,17,20}$ The mass spectra of the SG standards campesteryl, stigmasteryl and sitosteryl $3 \beta$-D-glucopyranosides are shown in Fig. 3. No molecular ions were observed in the mass spectra of the TMSi derivatives of SG, although they can be readily determined from low-abundance $[\mathrm{M}-15]^{+},[\mathrm{M}-15-90]^{+}$and $\left[\mathrm{M}-\mathrm{Me}-\mathrm{Me}_{3} \mathrm{SiOH}\right]^{+}$ions (at $\mathrm{m} / z$ 745, 757 and 759 for campesteryl, stigmasteryl and sitosteryl glucopyranoside, respectively). Loss of the sugar (TMSi) with charge retention on the sugar portion and the cleavage of the $\mathrm{C}-\mathrm{O}$ glycosidic bond produces an ion (at $m / z 451$ for hexoses) at low abundance, which subsequently loses trimethylsilanol $\left[\mathrm{Me}_{3-}\right.$ $\mathrm{SiOH}]$, producing another ion at $m / z 361$ which is prominent in all spectra. The ions at $m / z 451$ and 361 are also characteristic of the TMSi derivatives of many other types of natural hexose glycosides. ${ }^{21,22}$ The TMSi groups also give rise to an intense TMSi ion at $m / z 73$ and to an ion at $m / z 147$ formed by cleavage of two vicinal TMSi groups. On the other hand, cleavage of the sterol moiety with charge retention on the steroid would produce ions at $\mathrm{m} / \mathrm{z} 383,395$ and 397 from campesterol, stigmasterol and sitosterol, respectively, which are also prominent in the spectra. Finally, the high relative intensity of the fragment ion at $m / z 204$ and the lower abundance of that at $m / z 217$ confirms a pyranoside configuration, which is readily distinguishable from the furanoside one in which the fragment at $m / z 217$ is more prominent than the fragment at $m / z 204^{3}$

Copyright (C) 2001 John Wiley \& Sons, Ltd.
The mass spectrum of the SG peak from E. globulus wood extract clearly indicates that the aglycone moiety consisted of sitosterol, which is also the predominant sterol in both free and esterified forms. Other sterols present in eucalypt wood in both free and esterified form, such as stigmastanol, citrostadienol, cycloartenol and 24-methylenecycloartanol, were not found to form SG. This observation is in agreement with substrate specifity of UDP-glucose:sterol glucosyltransferases involved in SG synthesis. These enzymes preferentially glucosilate sterols or sterol-like molecules with a 3- $\beta$ hydroxy group and a planar ring system (with trans coupling of $\mathrm{A}$ and $\mathrm{B}$ rings, or a double bond at C-5), like sitosterol. ${ }^{2} \mathrm{On}$ the other hand, the sugar moiety of the SG from E. globulus wood consisted of D-glucose, which has been found to be the most important sugar in glycosylated plant sterols, ${ }^{20,23,24}$ although several other $\alpha$ - or $\beta$-linked glycosyl residues have also been reported (including $\beta$-D-galactopyranosyl, $\beta$-Dglucuronopyranosyl, $\alpha$-L-rhamnopyranosyl, $\alpha$-D-riburonofuranosyl, $\beta$-D-xylopyranosyl and $\alpha$-D-xyluronopyranosyl residues). ${ }^{20}$

ASG were also identified in the acetone extracts of $E$. globulus wood, although in lower amounts $(20 \mathrm{mg} / \mathrm{kg}$ wood) than SG (130 mg/ $\mathrm{kg}$ wood). Figure 4 shows a comparison of the total-ion chromatograms of a mixture of ASG standards (as TMSi derivatives) and the eucalypt wood extracts. The retention time and mass spectrum of the ASG peak present in eucalypt wood were identical to those of sitosteryl (6'-Opalmitoyl)-3 $\beta$-D-glucopyranoside. The mass spectra of the ASG standards are shown in Fig. 5, and are similar to those of the corresponding SG with the fragments typical of carbohydrate and sterol moieties, as described above. Additional fragments correspond to the loss of the sterol moiety with charge retention on the sugar producing an ion at $\mathrm{m} / \mathrm{z}$ 617, which subsequently loses trimethylsilanol $\left[\mathrm{Me}_{3} \mathrm{SiOH}\right]$ producing an ion at $\mathrm{m} / \mathrm{z} 527$, both indicative of a palmitoylglucose. Similarly to what occurs with SG, cleavage of the sterol moiety with charge retention on the steroid would produce the ions at $\mathrm{m} / \mathrm{z} 383,395$ or 397, characteristic of campesterol, stigmasterol or sitosterol, respectively. It is interesting to note that only palmitic acid has been found esterified to the glucose moiety in the ASG identified in eucalypt wood. In contrast, all the fatty acids present in $E$. globulus wood in the free form also formed SE, the major one being linoleic acid. ${ }^{4}$ The ASG fractions from various tissues of vascular plants usually contain a number of typical saturated and unsaturated fatty acids, mainly C16 and C18. Palmitate, oleate, linoleate, linolenate and stearate are present most frequently. However, it has been reported that in some plants the acyl components of ASG consisted exclusively of saturated fatty acids, mainly palmitic acid. ${ }^{2}$

According to Nilvebrant and Byström, ${ }^{15}$ about half of the SG originally present in wood can survive the kraft cooking conditions and be found intact in the pulp. Therefore, in the present work, we investigated the occurrence of SG and ASG in process waters and unbleached pulp after eucalypt kraft cooking. Figure 6 shows a region of the total-ion chromatograms of the silylated extracts from the process water and unbleached pulp samples selected for this study. Significant amounts of SG $(70 \mathrm{mg} / 10 \mathrm{~L}$ in process water and $110 \mathrm{mg} / \mathrm{kg}$ in unbleached pulp) were identified in all samples, with a 

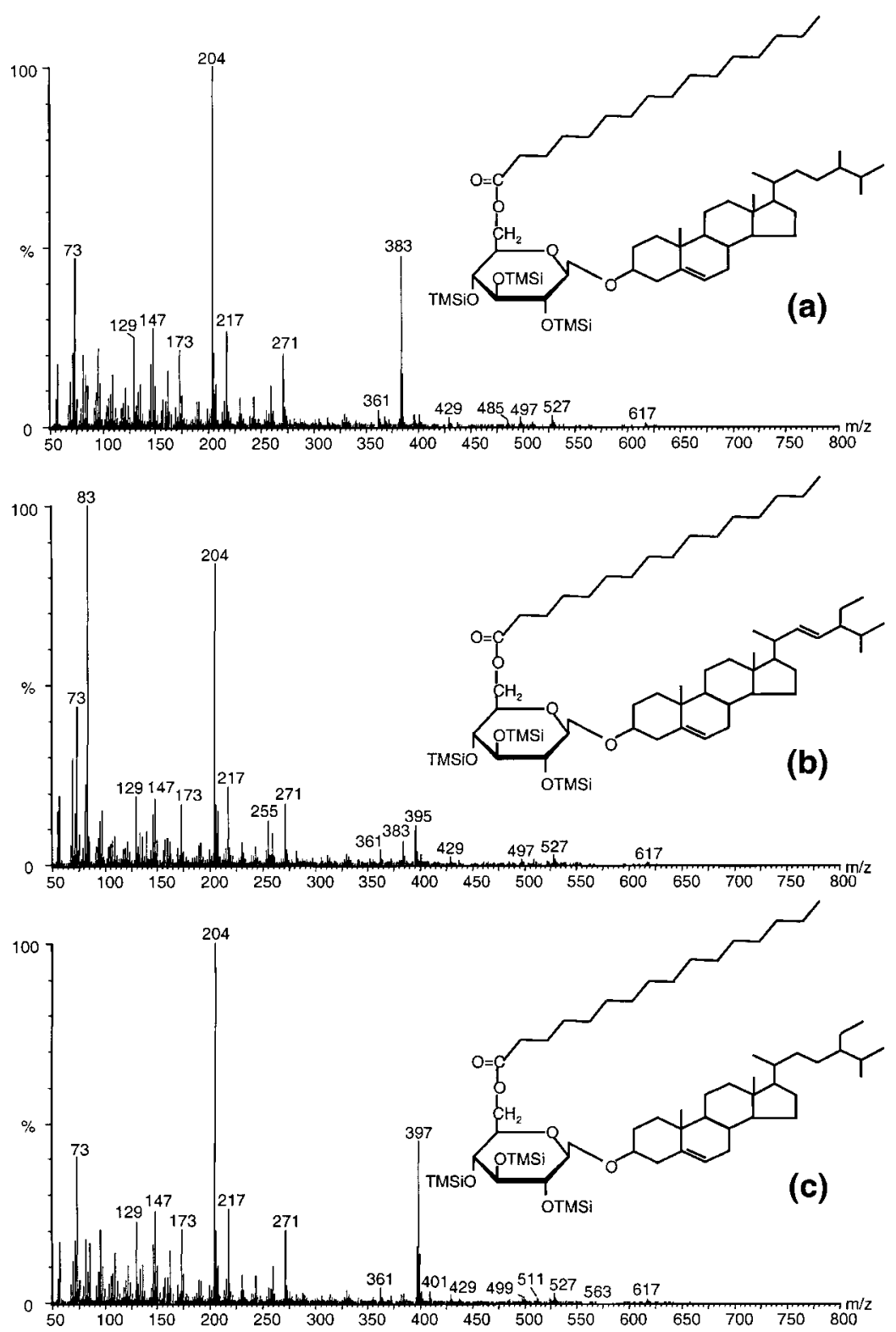

Figure 5. El mass spectra and structures of the TMSi ethers of (a) campesteryl (6'-O-palmitoyl)-3 $\beta$-D-glucopyranoside, (b) stigmasteryl (6'-Opalmitoyl)-3 $\beta$-D-glucopyranoside and (c) sitosteryl (6'-O-palmitoyl)-3 $\beta$-Dglucopyranoside.

composition similar to that from eucalypt wood. In all cases, the main peak was identified as sitosteryl $3 \beta$-D-glucopyranoside because of a mass spectrum (base peak at $\mathrm{m} / \mathrm{z} 204$ and prominent $\mathrm{m} / \mathrm{z} 397$ fragment) and relative retention time identical to those of the authentic standard. In contrast, no ASG could be detected in pulp and process water samples. The importance of the presence of SG after kraft pulping is due to their high hydrophilic-lipophilic balance (HLB), high melting point and very low solubility in water, alkali and the usual organic solvents. ${ }^{10}$ Due to these properties, SG constitute a part of protecting layers which prevent the cooking and bleaching chemicals from reaching the resin, and thereby keep them and other extractives in the pulp. ${ }^{15}$

\section{CONCLUSIONS}

In this paper, we have shown that medium-length hightemperature capillary columns with thin films are suitable for the rapid analysis of wood steryl glycosides (as TMSi derivatives) by GC/MS. Since the steryl glycosides can be detected, identified and quantified in a single chromatographic run, the method has advantages compared with those requiring fractionation of the steryl glycosides by TLC or solid-phase extraction, or hydrolysis before the analysis. The occurrence of sitosteryl $3 \beta$-D-glucopyranoside and sitosteryl (6'-O-palmitoyl)-3 $\beta$-D-glucopyranoside has been demonstrated for the first time to our knowledge in $E$. 

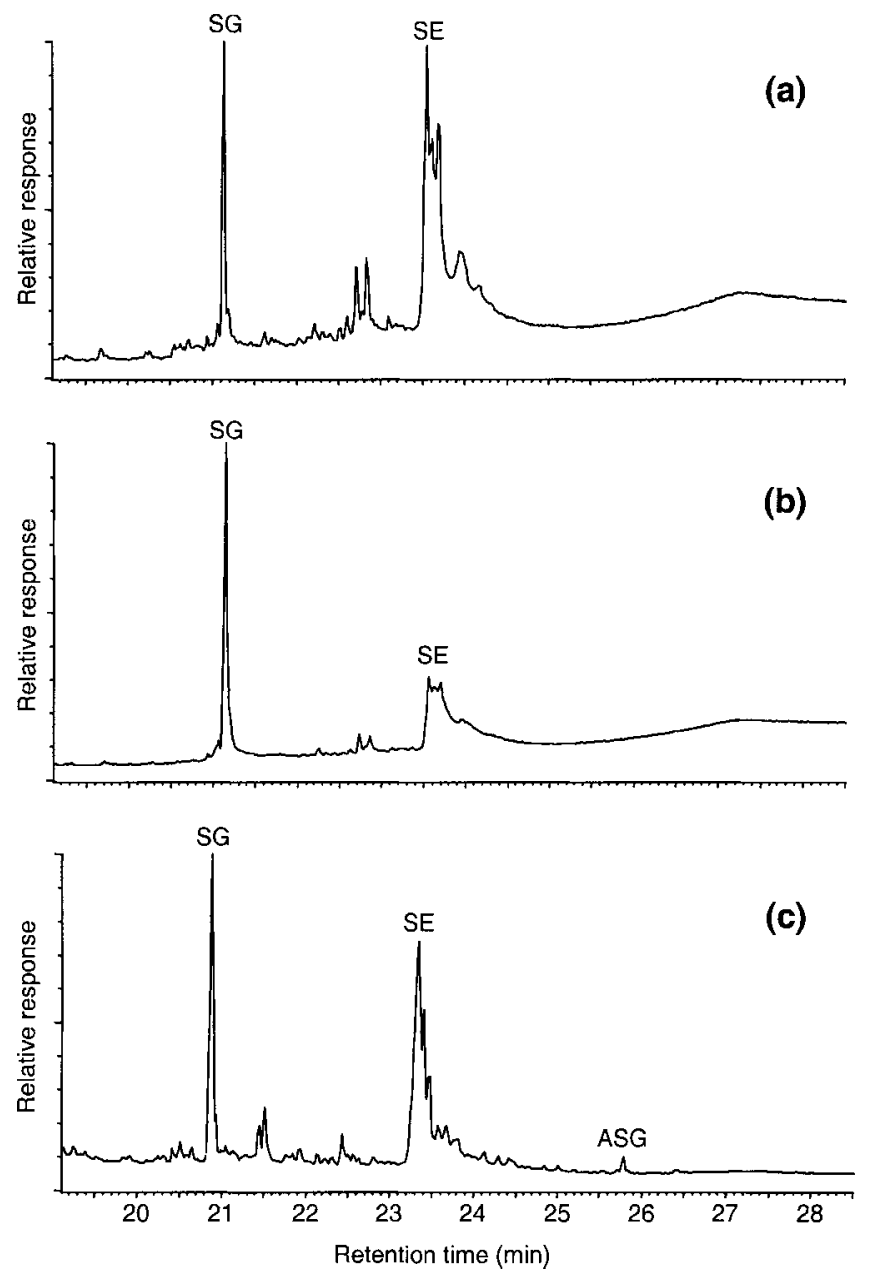

Figure 6. Partial gas chromatograms showing the distribution of SG, SE and ASG in the extracts from (a) process water and (b) unbleached pulp from E. globulus kraft cooking compared with (c) E. globulus wood extract (after BSTFA derivatization).

globulus wood. This is also the first time that SG have been identified after kraft cooking in unbleached pulps and process waters.

\section{Acknowledgements}

The authors thank B. Hermosín and C. Sáiz-Jiménez for GC/MS facilities and A. T. Martínez (CIB, CSIC, Madrid) for critical reading of the manuscript. This study has been supported by the European Commission (contract QLK5-991357) and the Spanish Comisión Interministerial de Ciencia y Tecnología (FEDER project 1FD97-0742).

\section{REFERENCES}

1. Elbein AD, Forsee WT, Schultz JD, Laine RA. Lipids 1975; 10: 427.

2. Wojciechowski ZA. In Physiology and Biochemistry of Sterols, Patterson GW, Nes WD (eds). Am. Oil Chem. Soc., Champaign, 1991; 361-395.

3. Dyas L, Threlfall DR, Goad LJ. Phytochemistry 1994; 35: 655.

4. Gutiérrez A, del Río JC, González-Vila FJ, Martín F. Holzforschung 1999; 53: 481.

5. del Río JC, Gutiérrez A, González-Vila FJ, Martín F, Romero J. J. Chromatogr. A 1998; 823: 457.

6. del Río JC, Gutiérrez A, González-Vila FJ. J. Chromatogr. A 1999; 830: 227.

7. del Río JC, Romero J, Gutiérrez A. J. Chromatogr. A 2000; 874: 235.

8. Gutiérrez A, Romero J, del Río JC. Holzforshung 2001; 55: 260.

9. Gutiérrez A, Romero J, del Río JC. Chemosphere 2001; 44: 1237.

10. Hillis WE, Sumimoto M. In Natural Products of Woody Plants II, Rowe JW (ed). Springer: Berlin, 1989; 880-920.

11. Abramovitch RA, Micetich RG, Smith SJ. Tappi 1963; 46: 37.

12. Braus H, Eck JW, Mueller WE, Miller FD. J. Agric. Food Chem. 1957; 5: 458.

13. Dutra NN, Alves HM, Carvalho MG, Filho RB. Quim. Nova 1992; 15: 10.

14. Seshadri TR, Vedantham TNC. Phytochemistry 1971; 10: 897.

15. Nilvebrant N-O, Byström S. In Proc. 8th Int. Symp. Wood and Pulping Chemistry, Helsinki, 1995; 135-140.

16. Saranpää P, Höll W. Trees 1987; 1: 215.

17. Laine RA, Elbein AD. Biochemistry 1971; 10: 2547.

18. Örså F, Holmbom B. J. Pulp Paper Sci. 1994; 20: J361.

19. Gutiérrez A, del Río JC, González-Vila FJ, Martín F. J. Chromatogr. A 1998; 823: 449.

20. Heinz E. In Advances in Lipid Methodology-Three Christie WW (ed). The Oil Press Ltd: Dundee, 1996; 211-332.

21. De Jongh DC, Radford T, Hribar JD, Hanessian S, Bieber M, Dawson G, Sweeley CC. J. Am. Chem. Soc. 1969; 91: 1728.

22. Niemelä K. Carbohydr. Res. 1989; 194: 37.

23. Grunwald C. Ann. Rev. Plant Physiol. 1975; 26: 209.

24. Staphylakis K, Gegiou D. Lipids 1985; 20: 723. 